\title{
Living Well to Keep Your Pressure Down
}

\author{
Linda B. Bobroff ${ }^{2}$
}

\section{Am I at Risk for High Blood Pressure?}

High blood pressure, or hypertension, can cause serious health problems. It makes your heart work harder and can damage your blood vessels even if you feel okay. Everyone should have their blood pressure checked regularly. If you have certain risk factors you are more likely to have high blood pressure. If any of the following risk factors for high blood pressure apply to you, discuss them with your health care provider:

- There is high blood pressure in my family.

- I'm a man over age 40.

- I'm a woman past menopause.

- I'm African-American.

- I'm obese.

- I'm physically inactive.

\section{Can I Decrease My Risk?}

You can decrease your risk of getting high blood pressure. Attaining these five goals can help you control your blood pressure and reduce your health risks:

1. Aim for a healthy weight.

2. Be physically active each day.

3. Choose and prepare foods with little salt.

4. Eat at least five fruits and vegetables every day; more is better.

5. If you drink alcoholic beverages, do so in moderation.

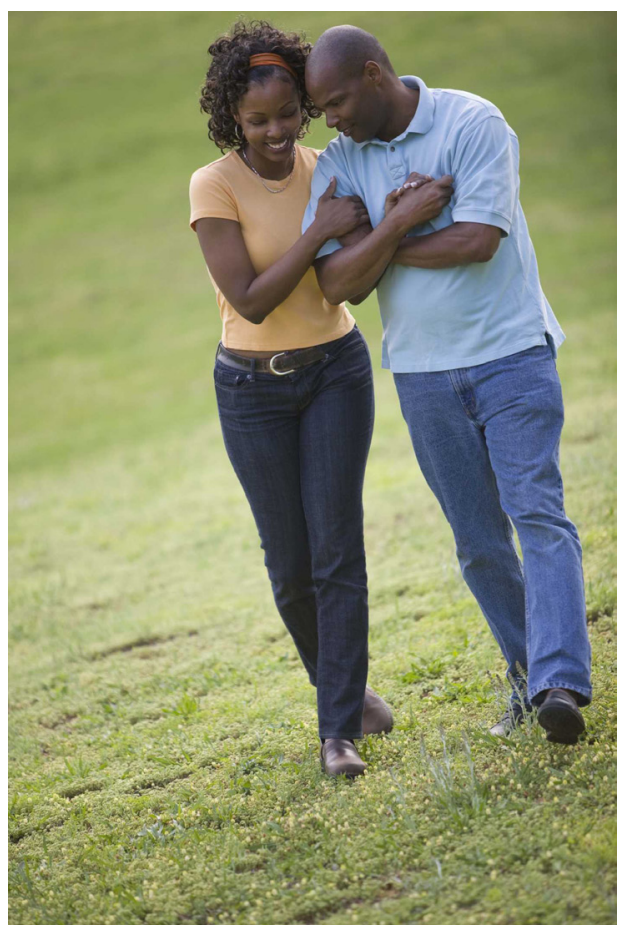

Figure 1. African-Americans are at high risk for high blood pressure. Being active and eating a healthful diet can reduce health risks. Credits: Jupiterimages, $\odot$ Getty Images

Working toward these goals will help keep you healthy. Your family will also benefit if they follow your lead and live a healthier lifestyle. Let's see how you can apply these rules to your life.

1. La version en español de este document es Viviendo Bien para Mantener su Presion Baja (FCS8690-Span). This document is FCS8690, one of a series of the Department of Family, Youth, and Community Sciences, Florida Cooperative Extension Service, Institute of Food and Agricultural Sciences, University of Florida. Original publication date August 2002. Latest revision January 2013. Visit the EDIS website at http://edis.ifas.ufl.edu.

2. Adapted from the NHLBI/NIH fact sheet "Facts About How to Prevent High Blood Pressure" by Linda B. Bobroff, PhD, RD, LD/N, professor, Department of Family, Youth, and Community Sciences, Florida Cooperative Extension Service, Institute of Food and Agricultural Sciences, University of Florida, Gainesville, FL 32611. 


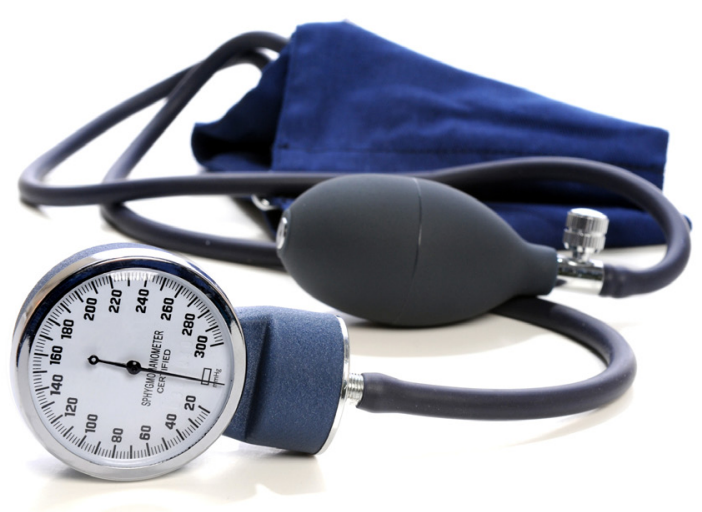

Figure 2. A health professional can take your blood pressure using a sphygmomanometer (sfig-mo-ma-nom-eter).

\section{Aim for a Healthy Weight}

As body weight increases, blood pressure tends to rise. If you are overweight, you can reduce your risk of high blood pressure by losing weight. Even losing a few pounds can help prevent high blood pressure. If you are overweight and already have high blood pressure, losing weight can help lower it.

There are charts you can use to see if you are within a healthy weight range for your height. The body mass index (BMI) is used as an estimate of body fat, which is the major health concern. To learn more about BMI and to use a BMI calculator, go to the Centers for Disease Control and Prevention website: http://www.cdc.gov/healthyweight/ assessing/index.html.

Think of a healthy weight as one that you can maintain with a healthy lifestyle and that keeps you at a low risk for disease. Ask yourself the following questions to see if you are at a healthy body weight:

1. Is my blood pressure normal?

2. Is my blood cholesterol normal?

3. Is my blood glucose (sugar) normal?

4. Can I do moderate exercise comfortably?

5. Can I maintain my weight without severe dieting?

6. Do I eat a variety of healthful foods in moderation?

7. Do I feel healthy?

If you answered "yes" to each question, then you probably are at a healthy weight for you. To maintain your health, follow the lifestyle recommendations in this fact sheet. If you answered "no" to one or more questions, then your weight may be putting you at risk for high blood pressure and other conditions. You may want to discuss your overall health with your doctor and ask for lifestyle suggestions.

\section{Be Physically Active Each Day}

A great way to start living a healthy lifestyle is to be more active. This section provides tips on how to include physical activity in your life. Being physically active will reduce your risk for high blood pressure and help keep you healthy. Here are a few of the benefits of being an active person:

- Attain/maintain normal blood pressure

- Attain/maintain normal blood cholesterol

- Decrease risk of heart attack, stroke, diabetes, and some types of cancer

- Help attain/maintain a healthy body weight

- Increase energy level

- Enhance sense of well-being

\section{HOW MUCH SHOULD I EXERCISE?}

Aim for at least 30 minutes of moderate physical activity most days of the week. Moderate physical activity increases your heart rate, but still allows you to talk while you are exercising. Examples are fast walking, weeding the garden, bicycling, and playing tennis. Most people will gain greater health benefits with longer or more vigorous activity. To get major health benefits, exercise moderately at least 150 minutes a week or vigorously 75 minutes a week. Keep in mind that you do not have to do all of your exercise at one time! You will get health benefits if you are active two or three times a day for a total of 30 or more minutes. Here is one example of how to do this:

\section{Walk the dog briskly (15 minutes).}

2. Walk during coffee break (15 minutes).

3. Perform stretches and lift light weights while watching or listening to the news (15-40 minutes).

Activities like swimming, brisk walking, running, bicycling, dancing, and jumping rope are "aerobic" exercise, which means they require oxygen. These types of activities condition your heart and lungs, protecting you against heart disease. Many people find it helpful to keep track of their activity using an activity log (see the table below for an example).

My Activity Log.

\begin{tabular}{|l|l|l|}
\hline \multicolumn{1}{|c|}{ Day/Date } & \multicolumn{1}{|c|}{ Activity/Activities } & \multicolumn{1}{c|}{ Amount/Duration } \\
\hline Mon. 1/24 & Walked dog & $15 \mathrm{~min}$. \\
& Played catch & $10 \mathrm{~min}$. \\
\hline Wed. 1/26 & Gardened & $20 \mathrm{~min}$. \\
& Walked dog & $15 \mathrm{~min}$. \\
\hline Thurs. 1/27 & Walked up stairs & 3 flights \\
& Vacuumed to music & 10 min. \\
\hline
\end{tabular}


Light activities, if done daily, can also help keep you fit and lower your risk for high blood pressure. To increase your daily activity, start doing some of these:

- Use stairs instead of elevators.

- Get off the bus one or two stops early and walk the rest of the way.

- When shopping, park at the back of the parking lot.

- Ride a bike to the store, to work, or for fun.

- Work in the yard or garden.

- Move to your favorite music as you clean the house.

- Play actively with your children.

\section{DO I NEED TO SEE MY DOCTOR FIRST?}

Most people don't need to see a doctor before they start exercising. A gradual, sensible exercise program has few health risks. Do check with your doctor first if any of the following apply:

- You plan to start a vigorous activity plan and have a chronic health problem such as heart disease, high blood pressure, diabetes, osteoporosis, or obesity.

- You are at high risk for heart disease (have a personal or family history, smoke cigarettes, have a sedentary lifestyle, or have abnormal blood lipids).

- You feel dizzy or faint when you are physically active.

- You get breathless after a mild workout.

- You are a man over 40 years of age or a woman over 50 .

\section{Choose and Prepare Foods with Little Salt}

Americans eat more salt (sodium chloride) than they need. They also have higher rates of high blood pressure than people in other countries. Often, when people with high blood pressure cut back on salt, their blood pressure falls.

Eating less salt also can prevent blood pressure from rising in the first place. African-Americans and older adults often are more affected by salt in the diet than others. There's no way to tell who will get high blood pressure when they eat too much salt. It is recommended that everyone keep their intake of salt moderate.

\section{HOW MUCH SALT OR SODIUM IS RECOMMENDED?}

Young adults should consume less than one teaspoon of salt a day. This is about 2,300 milligrams (mg) of sodium, much less than most Americans consume. Persons with high blood pressure, African-Americans, and middle-aged and older adults should aim for no more than 1,500 mg of sodium per day.

Much of the salt we get in our diets comes from packaged foods and restaurants. Doing more home cooking using low-salt ingredients can help you control the amount of salt in your diet. Additional suggestions are provided in Table 1.

Table 1. Ways to Decrease Your Salt Intake

\begin{tabular}{|c|c|}
\hline At the Store & $\begin{array}{l}\text { Choose fresh, frozen, or canned } \\
\text { vegetables without added salt or } \\
\text { sauces. } \\
\text { Choose fresh or frozen fish, shellfish, } \\
\text { poultry, and meat. } \\
\text { Read the Nutrition Facts label to } \\
\text { compare the amount of sodium } \\
\text { in processed foods like frozen } \\
\text { dinners, soups, cereals, and sauces. } \\
\text { Salt content varies widely. Be sure } \\
\text { to check the serving size when } \\
\text { comparing foods! Look for labels } \\
\text { that say “low-sodium."These foods } \\
\text { contain } 140 \text { milligrams of sodium or } \\
\text { less per serving. } \\
\text { Ask your grocer or supermarket } \\
\text { manager to offer more low-sodium } \\
\text { foods. }\end{array}$ \\
\hline Cooking and Eating at Home & $\begin{array}{l}\text { Use little or no salt in cooking or at } \\
\text { the table. Instead, use spices and } \\
\text { herbs to enhance the flavor of food. } \\
\text { Salt in many recipes can be reduced } \\
\text { without loss of quality, although } \\
\text { certain recipes may require some } \\
\text { salt. When using salt, be sure to use } \\
\text { the iodized form. } \\
\text { Go easy on condiments such as soy } \\
\text { sauce, ketchup, pickles, and olives. } \\
\text { Leave the salt shaker in a cupboard! }\end{array}$ \\
\hline Eating Out & $\begin{array}{l}\text { Choose plain foods like grilled } \\
\text { or roasted entrees. Combination } \\
\text { dishes like stews or pasta tend to be } \\
\text { high in salt. } \\
\text { Ask to have no salt added when the } \\
\text { food is prepared. }\end{array}$ \\
\hline Snacking & $\begin{array}{l}\text { Choose fruits and vegetables } \\
\text { (without added salt) instead of salty } \\
\text { snacks most of the time. } \\
\text { Drink water; it is usually very low in } \\
\text { sodium. Check the label on bottled } \\
\text { water for sodium content. }\end{array}$ \\
\hline
\end{tabular}

\section{Eat at Least Five Fruits and Vegetables Every Day}

Eating lots of fruits and vegetables each day can help keep your blood pressure low. It also can help lower high blood pressure if it already is high. Select a variety of fresh fruits and vegetables in season and locally grown when possible. This will give you the most nutrients and also will keep costs lower. Canned (without salt or added sugars) and frozen choices also are good options. 


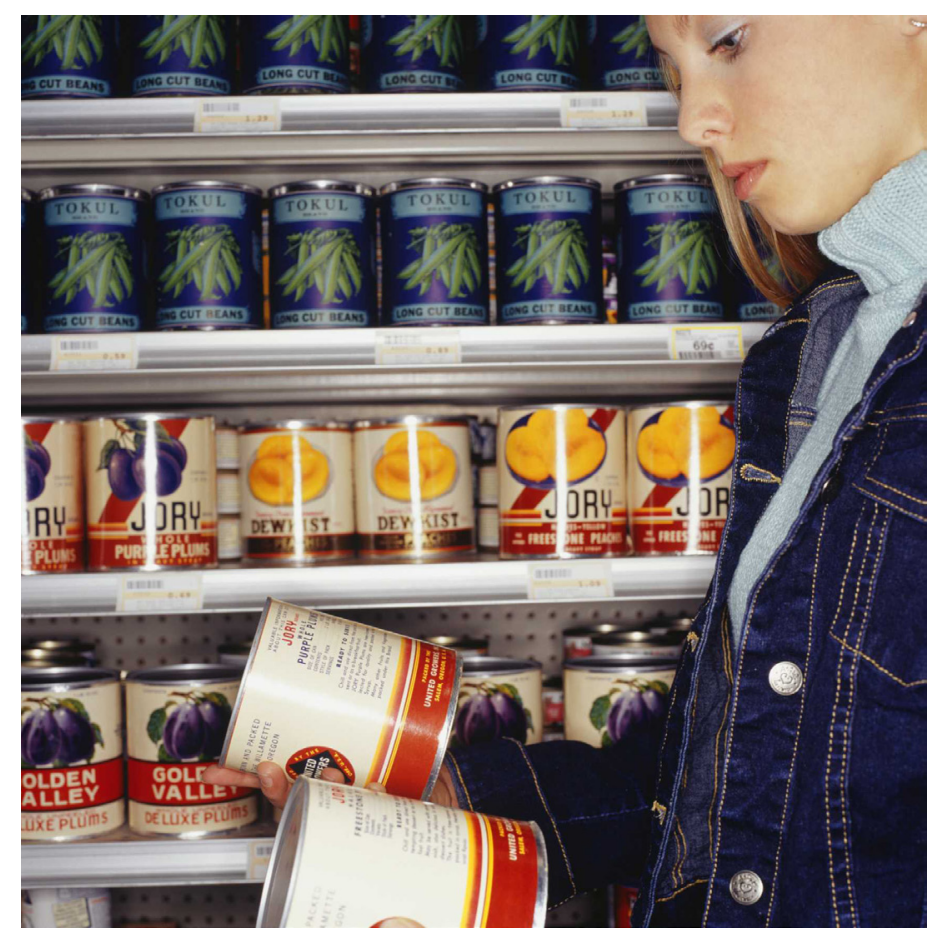

Figure 3. Check the Nutrition Facts panel to compare sodium content in different brands when buying canned foods. Choose reduced- or low-sodium foods often. Credits: Ryan McVay

\section{HOW MANY FRUITS AND VEGETABLES DO I NEED TO EAT?}

Eat at least $1 \frac{1}{2}$ cups of fruit and 2 cups of vegetables each day. More is better for decreasing risk of high blood pressure. Recommended intake from each food group depends on your calorie needs. To find the calorie level right for you and the amount of food to eat from each food group, visit: http://www.ChooseMyPlate.gov.

\section{HOW CAN FRUITS AND VEGETABLES HELP KEEP MY BLOOD PRESSURE LOW?}

Fruits and vegetables are naturally low in sodium and contain minerals like potassium, magnesium, and calcium that can help lower blood pressure. They are also naturally low in fat, and can help with managing your weight.

Here are some tips for adding fruits and vegetables to your daily diet:

- Add fresh berries or sliced banana to your cereal in the morning.

- Snack on dried fruit like apricots, raisins, or dried plums/ prunes (try the flavored kind for a treat).

- Keep washed and cut-up carrot and celery sticks in the refrigerator at work and home for a quick healthy snack.

- Order a salad instead of French fries if you have fast food.

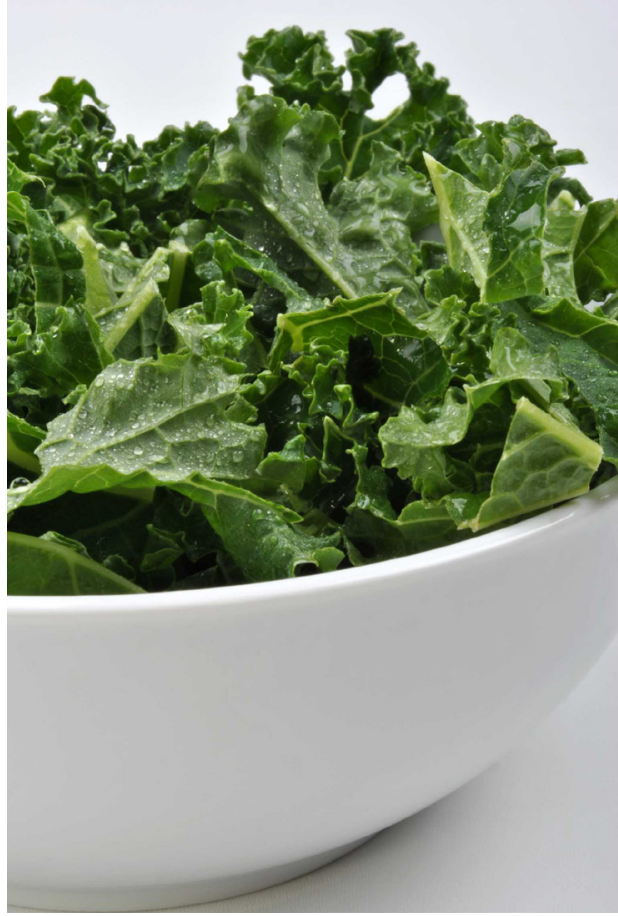

Figure 4. Kale is a rich source of calcium and many other nutrients. These kale leaves are washed and ready to cook.

- Have boxes of $100 \%$ fruit juice handy for a healthy drink break.

- Keep fresh fruit available in the refrigerator (except bananas) for a quick healthy snack.

- Add extra fresh or frozen vegetables when you make "from scratch" or pre-packaged soups, stews, and other mixed dishes.

\section{If You Drink Alcoholic Beverages, Do So Sensibly and in Moderation}

Drinking too much alcohol can lead to high blood pressure. If you drink alcohol at all, men should have no more than two drinks a day and women should have no more than one drink a day.

What counts as a drink?

- $1 \frac{1 / 2}{2}$ ounces of 80 -proof distilled spirits

- 5 ounces of wine

- 12 ounces of beer (regular or light)

\section{BUT ISN'T DRINKING ALCOHOL GOOD FOR MY HEART?}

Moderate drinking of red wine may lower the risk of heart disease for some people. But other practices can also reduce the risk of heart disease. These include eating a healthy diet, being physically active, not smoking, and maintaining a healthy weight. People who are unable to drink moderately should not drink at all. 


\section{What Are Other Ways to Reduce Risk of High Blood Pressure?}

Other practices that help prevent high blood pressure include the following:

\section{Get Your Minerals from Foods!}

The minerals potassium, magnesium, and calcium may play a role in keeping blood pressure down. Include food sources of these minerals every day.

For potassium, eat:

- a variety of fruits and vegetables

- fish, lean pork, and veal

- dry peas and beans (legumes)

- low-fat milk

For magnesium, eat:

- whole-grain foods

- nuts and seeds

- dry peas and beans

For calcium, eat:

- low-fat milk, yogurt, and cheese

- green leafy vegetables

- calcium-fortified foods, including orange juice, tofu, breads, and cereals

People with low calcium intakes tend to have high blood pressure. Get the recommended amount of calcium every day from the foods you eat. If your calcium needs are high, a calcium supplement can help to meet your goal, but it may not affect your risk for high blood pressure. See Table 2 for your daily recommended amount of calcium.

Table 2. Recommended Calcium Intake*

\begin{tabular}{|c|c|}
\hline Age (years) & Calcium (milligrams/day) \\
\hline $9-18$ & 1,300 \\
\hline $19-50$ & 1,000 \\
\hline 51-70 (males) & 1,000 \\
\hline 51-70 (females) & 1,200 \\
\hline Over 70 & 1,200 \\
\hline \multicolumn{2}{|c|}{$\begin{array}{l}\text { Source: Food and Nutrition Board, Institute of Medicine, National } \\
\text { Academies. Dietary Reference Intakes (DR/s): Recommended Dietary } \\
\text { Allowances and Adequate Intakes, Elements, http://fnic.nal.usda.gov/ } \\
\text { dietary-guidance/dietary-reference-intakes/dri-tables } \\
\text { *Post-menopausal women who are not on hormone replacement } \\
\text { therapy may have higher calcium needs; check with your doctor. }\end{array}$} \\
\hline
\end{tabular}

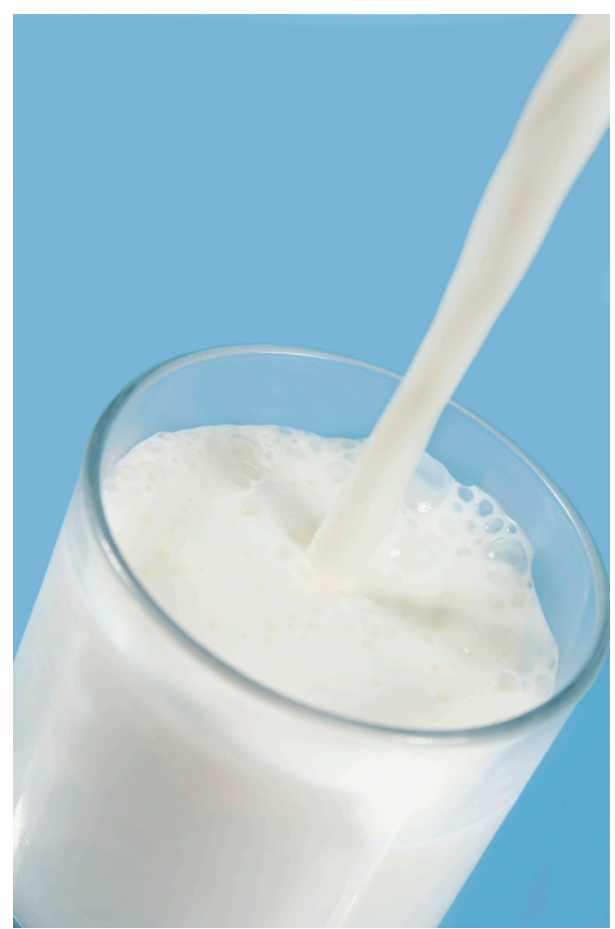

Figure 5. Milk is an excellent source of calcium, which may help keep blood pressure in the normal range. Choose fat-free or low-fat (1\%) milk to limit fat and calories.

\section{Practice Stress Management}

Stress can cause your blood pressure to rise. Over time, high levels of stress may contribute to high blood pressure. Stress management techniques include relaxation and meditation. They may not prevent high blood pressure, but they feel good and may help you stick to an exercise or weight management program that can help you manage your blood pressure.

Follow all of these recommendations to help reduce your risk for high blood pressure. The healthy lifestyle practices discussed here also will lower your risk for heart disease and stroke.

\section{Want to Know More?}

Check out these resources for more information on high blood pressure, weight management, or physical activity, or to get healthy recipes and eating tips for healthy living.

\section{National Heart, Lung, and Blood Institute Information Center}

The NHLBI website provides information on heart, vascular, lung, and blood diseases, consumer publications, and recipes.

Phone: (301) 592-8573

Website: http://www.nhlbi.nih.gov 


\section{U.S. Department of Health and Human Services Healthfinder}

This site contains information about over 1,600 health topics (some in Spanish), interactive health tools, and health services such as locating a doctor.

Website: http://www.healthfinder.gov

\section{National Stroke Association}

This site has information about prevention, signs and symptoms, and recovery.

Phone: 1-800-STROKES

Website: http://www.stroke.org

\section{Fruits and Veggies: More Matters}

This site includes meal planning, shopping, recipes, cooking, getting kids involved, and resources to help increase fruit and vegetable intake.

Website: http://www.fruitsandveggiesmorematters.org

\section{Physical Activity Guidelines for Americans}

This report from the U.S. Department of Health and Human Services offers the first-ever physical activity guidelines for Americans. It is now available in English and Spanish.

Website: http://www.health.gov/paguidelines/

Call your county Extension Family and Consumer Sciences (FCS) agent to see what healthy lifestyles educational programs are offered in your county. Your county Extension office should be listed in your telephone book, under county government. In Florida you can find the location and contact information for the Extension office in your county at: http://solutionsforyourlife.ufl.edu/map/. 